\title{
Influence of plant growth regulators on volatiles produced by in vitro grown shoots of Agastache rugosa (Fischer \& C.A.Meyer) O. Kuntze
}

\author{
Sylwia Zielińska $\cdot$ Ewelina Piątczak • \\ Danuta Kalemba • Adam Matkowski
}

Received: 21 June 2010/ Accepted: 2 March 2011/Published online: 23 April 2011

(C) The Author(s) 2011. This article is published with open access at Springerlink.com

\begin{abstract}
The composition of volatile organic compounds emitted by in vitro shoots of Agastache rugosa (Fischer \& C.A. Meyer) O. Kuntze (Lamiaceae) was studied using headspace solid-phase microextraction-gas chromatography-mass spectrometry and compared to the those emitted by adult plants and in vitro-germinated seedlings. Shoot-tip explants were cultured on a solid MS medium supplemented with either $4.4 \mu \mathrm{M}$ 6-benzyladenine (BA), $9.3 \mu \mathrm{M}$ kinetin, or $0.45 \mu \mathrm{M}$ thidiazuron and with either $0.57 \mu \mathrm{M}$ indole-3-acetic acid (IAA) or $0.41 \mu \mathrm{M}$ picloram. Shoot proliferation was observed in all these treatments. The presence of these plant growth regulators in the culture medium significantly influenced the composition of volatiles as well as morphogenetic responses observed. The number and quality of regenerating shoots and frequency of axillary bud break were highest in medium containing the BA + IAA combination. Sixty-five compounds were identified in the headspace of the in vitroproduced material and plants cultivated in the field. The in vitro shoots emitted both hydrocarbon (limonene, $\alpha$-pinene) and oxidized (menthone, isomenthone, pulegone)
\end{abstract}

S. Zielińska · A. Matkowski (

Department of Pharmaceutical Biology and Botany, Medical

University in Wroclaw, Al. Jana Kochanowskiego 10, 51-601

Wroclaw, Poland

e-mail: pharmaceutical.biology@wp.eu

E. Piątczak

Department of Biology and Pharmaceutical Botany, Medical University of Lodz, ul. Muszynskiego 1, 90-151 Lodz, Poland

D. Kalemba

Institute of General Food Chemistry, Technical University

of Lodz, ul. Stefanowskiego 4/10, 90-924 Lodz, Poland monoterpenes. The composition of monoterpenes differed depending on the type of auxin-rather than cytokinin-in the medium. The emission of phenylallyl compounds, such as estragole, a major compound in field-grown plants, was markedly lower in shoot cultures.

Keywords Agastache rugosa - In vitro shoots . Monoterpenes · Phenylpropenes · Auxin · Cytokinin

\begin{tabular}{|c|c|}
\hline \multicolumn{2}{|l|}{ Abbreviations } \\
\hline BA & 6-Benzyladenine \\
\hline EG & Estragole \\
\hline HS-VOC & $\begin{array}{l}\text { Headspace volatile organic } \\
\text { compounds }\end{array}$ \\
\hline HS-SPME-GC-MS & $\begin{array}{l}\text { HS solid-phase microextraction-gas } \\
\text { chromatography-mass spectrometry }\end{array}$ \\
\hline IAA & Indole-3-acetic acid \\
\hline KIN & Kinetin \\
\hline MS & $\begin{array}{l}\text { Murashige and Skoog (1962) } \\
\text { medium }\end{array}$ \\
\hline PGRs & Plant growth regulators \\
\hline PIC & Picloram \\
\hline TDZ & Thidiazuron \\
\hline
\end{tabular}

\section{Introduction}

Agastache rugosa (Fischer \& C.A. Meyer) O. Kuntze (Lamiaceae) (also known as giant hyssop or Korean mint) is widely distributed throughout East Asia and is used locally as a herbal drug and spice. It has antibacterial and antifungal activity (Shin 2004; Song et al. 2001) and is used against fever, headache, stomach pain and other gastrointestinal disorders (Dung et al. 1996). 
Essential oil and headspace volatile organic compounds (HS-VOCs) of A. rugosa usually contain estragole (methyl chavicol) as a major compound (Dung et al. 1996; Song et al. 2001; Wilson et al. 1992). Chae et al. (2005) grouped Korean A. rugosa plants into five chemotypes, namely, estragole, menthone, menthone plus pulegone, methyleugenol, and methyleugenol plus limonene. The methyleugenol chemotype of $A$. rugosa has also been described by Weyerstahl et al. (1992). In A. rugosa grown in Scotland from seeds of various sources (Svoboda et al. 1995), estragole (EG) was the main component in most samples, with some samples also containing isomenthone and pulegone. The content of isomenthone increased during development from 8.5 to $45 \%$.

The composition of VOC impacts the quality and bioactivity of aromatic herbs and essential oils. The complexity of the emitted mixtures is also crucial for protecting the plant from pests and attack by pathogens. Therefore, many efforts have been made to discover the mechanisms of VOC regulation. In vitro methodology provides a useful tool for investigating individual factors at work during volatile biosynthesis (Predieri and Rapparini 2007). However, the secondary metabolite profile of in vitro-grown plants is usually altered in comparison that of free-grown plants, although the detailed mechanism of this phenomenon is not fully understood (Morone-Fortunato and Avato 2008; Nitnaware et al. 2011; Sood and Chauhan 2010).

The aim of this study was to compare the chemical composition of HS-VOCs emitted by in vitro shoot cultures of A. rugosa grown on media containing one of two auxins - natural indole-3-acetic acid (IAA) and the auxinic herbicide picloram (PIC) — and one of three cytokininskinetin (KIN), 6-benzyladenine (BA), and thidiazuron (TDZ). The morphogenetic response to each plant growth regulator (PGR) treatment was also observed. The VOC profile was compared to that of field-grown adult plants and of in vitro-raised seedlings, and the influence of in vitro conditions on the proportions of phenylallyl volatiles and monoterpenes as well as on the proportions of the different monoterpenes was analyzed and discussed.

\section{Materials and methods}

Plant material

Agastache rugosa plants were cultivated in the Botanical Garden of Medicinal Plants (BGMP) at the Department of Pharmaceutical Biology and Botany in Wroclaw, Poland. For the HS-VOC analysis we used 4-week-old seedlings obtained from in vitro-germinated seeds, shoots of A. rugosa obtained by in vitro multiplication, and leaves of a 3-year-old flowering plant cultivated in the field.
Establishment of in vitro germinated seedlings and shoot cultures

Seeds were surface sterilized with $5 \%$ sodium hypochlorite, rinsed with sterile distilled water, and sown on basal MS (Murashige and Skoog 1962) medium containing $30 \mathrm{~g} /$ L sucrose and $6 \mathrm{~g} / \mathrm{L}$ agar (LAB-AGAR, Biocorp, Poland). Four-week-old in vitro-germinated seedlings were used for volatile extraction and for the establishment of shoot cultures. Shoot tips with an apical bud and two axillary buds were excised and individually transferred to a shoot proliferation medium in $40 \times 300-\mathrm{mm}$ culture tubes. The proliferation medium consisted of MS basal medium without plant growth regulators (MS0) or supplemented with specific concentrations of one of three cytokinins, namely, $4.4 \mu \mathrm{M}$ BA, $9.3 \mu \mathrm{M} \mathrm{KIN}$, or $0.45 \mu \mathrm{M}$ TDZ, together with one of two auxins, i.e., IAA $(0.57 \mu \mathrm{M})$ or PIC $(0.4 \mu \mathrm{M})$. These PGRs and the concentrations were previously identified in a preliminary experiment as optimal for yielding sufficient shoots that would allow for determination of the emission of volatile compounds (data not shown).

Cultures were maintained at $25 \pm 2{ }^{\circ} \mathrm{C}$ under a $16 / 8$-h (light/dark) photoperiod with cool-fluorescent light supplied by ILD 18 W/54 lamps (Philips Lighting, Paris, France) at a photon flux density of $40 \mu \mathrm{M} \mathrm{m}^{-2} \mathrm{~s}^{-1}$. After 28 days of culture, data were recorded on the number of axillary bud break, number of shoots and buds per explant, and number of adventitious buds per callus formed at the basal ends of explants. Shoots shorter than $3 \mathrm{~mm}$ in length were designated as buds.

All data were subjected to statistical analysis using a one-way analysis of variance (ANOVA) followed by the Mann-Whitney $U$-test and Kruskal-Wallis nonparametric (distribution free) tests. The calculated percentages of axillary bud break and callus formation were compared using the chi-square nonparametric test (Statistica ver. 8.0; Statsoft, Tulsa, OK). The statistical significance of differences between treatments were considered significant at $P \leq 0.05$.

HS solid-phase microextraction-gas

chromatography-mass spectrometry

The volatiles were extracted using a manual solid-phase microextraction (SPME) technique which consists of a fiber coated with 50/30- $\mu \mathrm{m}$ divinylbenzene-carboxenpolydimethylsiloxane (DVB/CAR/PDMS) mounted in a syringe-like device (Supelco, Bellefonte, PA). Fresh material $(100 \mathrm{mg}$ ) was placed in a $15-\mathrm{mL}$ sealed vial, and the sample incubated at $60^{\circ} \mathrm{C}$ for $15 \mathrm{~min}$ and then equilibrated with the fiber immersed in the headspace for $30 \mathrm{~min}$. The volatiles were thermally desorbed in the injector of the 
chromatograph for $10 \mathrm{~min}$. Gas chromatography (GC) analysis was performed using a Trace GC Ultra oven with DSQ II mass spectrometer (MS) (Thermo Electron, Waltham, MA) with a SSL (split-splitless) injector, flame ionization (FID), and mass selective detectors, and FIDMS splitter (SGE Analytical Science, Melbourne, Australia). Operating conditions included a Rtx-1 ms capillary column (Restek; Thermo Fisher Scientific, Waltham, MA) $60 \mathrm{~m} \times 0.25 \mathrm{~mm}$; film thickness $0.25 \mu \mathrm{m}$; temperature program $60^{\circ} \mathrm{C}(4 \mathrm{~min})$ up to $300^{\circ} \mathrm{C}$ at $4^{\circ} \mathrm{C} / \mathrm{min}$; injector temperature $250^{\circ} \mathrm{C}$; FID temperature $300^{\circ} \mathrm{C}$; carrier gas $\mathrm{He}_{2}$ at a regular pressure of $200 \mathrm{kPa}$; split ratio 1:20. Mass spectra (ionization voltage $70 \mathrm{eV}$; ion sources temp $200^{\circ} \mathrm{C}$ ) were acquired over the mass range 30-4,000 Da. Identification was based on the comparison of the retention indices (RI) and mass spectra with available libraries (Wiley 8th edn, NIST 05, MassFinder 4) and with literature data (Adams 2007). A quantitative analysis (expressed as percentages of each component) was carried out by peak area normalization measurements without correction factors. Three replicates were done for each different medium, and the relative standard deviation (RSD) was calculated for compounds exceeding $1 \%$.

\section{Results and discussion}

In vitro shoot proliferation

Supplementation of the culture media with BA resulted in the highest number of lateral shoots and about $70 \%$ of explants forming axillary shoots (Table 1). On media containing other cytokinins, both the percentage of axillary bud break of explants and mean number of shoots were lower.
The highest and second highest number of developing axillary shoots were obtained after 4 weeks of culture on BA/IAA and BA/PIC, respectively; the difference was not significant (Table 1). The cytokinin BA has also been used for shoot multiplication of other Lamiaceae, including Salvia sclarea (Liu et al. 2000), S. officinalis (Santos-Gomes and Fernandes-Ferreira 2003), Rosmarinus officinalis (Misra and Chaturvedi 1984), Melissa officinalis (Meszaros et al. 1999), and Lavandula dentata (Sudria et al. 1999). In terms of A. rugosa shoot induction, supplementation with BA was superior to that with KIN . The use of KIN resulted in a lower number of shorter shoots with palegreen leaves with white sectors and in more intensive callus formation. A similar effect was observed by Misra and Chaturvedi (1984) for $R$. officinalis and by Meszaros et al. (1999) for M. officinalis.

Supplementation with the cytokinine TDZ was the least efficient treatment in terms of shoot induction and multiplication, resulting in malformed, light-green stems and leaves. The number of shoots per explant was significantly lower on medium containing TDZ than on medium containing BA (Table 1). Differences in reactions to various kinds of cytokinins are frequent during in vitro shoot organogenesis in plants and have been reviewed recently by Magyar-Tabori et al. (2010). Adventitious shoot organogenesis occurred on callus formed at the basal part of explants grown on all media containing PGRs. The number of adventitious buds per callus was highest on medium containing BA, followed by medium containing KIN and TDZ. Additionally, the total shoot number per explant was higher on IAA than on PIC, for all cytokinins. Despite the suboptimal performance of in vitro shoots on KIN and TDZ media, the cultures were used for comparative volatile analysis.

Table 1 Effect of growth regulators on multiple shoot formation by shoot-tip explants of Agastache rugosa cultured for 4 weeks on Murashige and Skoog (1962) medium

\begin{tabular}{|c|c|c|c|c|c|}
\hline $\begin{array}{l}\text { Cytokinin } \\
(\mu \mathrm{M})\end{array}$ & $\begin{array}{l}\text { Auxin } \\
(\mu \mathrm{M})\end{array}$ & $\begin{array}{l}\text { Number of } \\
\text { explants in culture }\end{array}$ & $\begin{array}{l}\text { Axillary bud } \\
\text { break }(\%)\end{array}$ & $\begin{array}{l}\text { Mean number of axillary } \\
\text { shoots/explant }\end{array}$ & $\begin{array}{l}\text { Mean number of } \\
\text { adventitious buds/callus }\end{array}$ \\
\hline \multirow[t]{2}{*}{ BA, 4.4} & IAA, 0.57 & 46 & 69.56 & $3.46 \pm 0.95 \mathrm{a}$ & $6.44 \pm 1.00 \mathrm{a}$ \\
\hline & PIC, 0.41 & 40 & 72.50 & $3.13 \pm 0.27 \mathrm{a}$ & $3.04 \pm 0.40 \mathrm{~b}$ \\
\hline \multirow[t]{2}{*}{ KIN, 9.3} & IAA, 0.57 & 45 & 53.33 & $1.91 \pm 0.14 \mathrm{~b}$ & $3.31 \pm 0.24 b$ \\
\hline & PIC, 0.41 & 34 & 48.38 & $1.66 \pm 0.18 b$ & $2.88 \pm 0.42 \mathrm{~b}$ \\
\hline \multirow[t]{2}{*}{ TDZ, 0.45} & IAA, 0.57 & 26 & 33.33 & $1.33 \pm 0.20 \mathrm{~b}, \mathrm{c}$ & $2.75 \pm 0.40 \mathrm{~b}$ \\
\hline & PIC, 0.41 & 22 & 9.09 & $1.5 \pm 0.49 \mathrm{~b}$ & $2.12 \pm 0.35 \mathrm{~b}$ \\
\hline 0 & 0 & 37 & 18.91 & $1.0 \pm 0.00 \mathrm{c}$ & $0.0 \pm 0.00 \mathrm{c}$ \\
\hline
\end{tabular}

BA 6-Benzyladenine, KIN kinetin, TDZ thidiazuron, IAA indole-3-acetic acid, PIC picloram

Data are expressed as the mean \pm standard error (SE). Mean numbers of shoots/buds followed by the same letters within a column are not significantly different $(P \geq 0.05)$ according to Kruskal-Wallis nonparametric (distribution free) test (no. of axillary shoots) and Mann-Whitney $U$ test (no. of buds). The values on percentage of axillary bud break are significantly different from those of the control using chi-square test 
Composition of volatiles

The 65 identified compounds and their mean contents are listed in Table 2 in order of their elution from the GC column. The RSD for compounds present at amounts exceeding $1 \%$ did not exceed $5 \%$. We observed two main trends in VOC composition: (1) there were remarkable differences in the composition of VOCs between the adult plant, seedling, and in vitro shoot cultures; (2) there were complex variations in the proportions of individual compounds between in vitro shoots cultured with different auxins and cytokinins.

With respect to the first observation, the predominance of a phenylallyl compound typical of this species, namely, estragole, was confirmed in an adult plant (Wilson et al. 1992). The second in abundance was a monoterpene hydrocarbon, limonene, which constituted only $3.7 \%$, while none of the remaining compounds exceeded $0.2 \%$. In the seedlings, the proportion of EG was reduced to $21 \%$, whereas an oxidized monoterpene, pulegone, was the most prevalent $(71.3 \%)$, and the limonene content was comparable to that in the fully developed plant. In the in vitro cultures, The most obvious difference between in vitro cultures and adult plants/seedlings was an almost complete absence of phenylallyl volatiles in the former-either EG or any other. Only the culture on the TDZ/PIC combination emitted a small amount $(0.7 \%)$ of trans-anethole, while all others emitted at most $0.1 \%$ or trace amounts of either EG or trans-anethole. Instead, monoterpenes constituted the great majority of volatiles. Regardless of the plant material, the major compounds were accompanied by several sesquiterpenoids as well as aliphatic (C5, C6, C7, C8, C9) alcohols, aldehydes, esters, and ketones (some of which are known as green leaf volatiles), none of which exceeded $1 \%$ of the total VOCs. In essential oil from a related species, $A$. anethiodora, a drastic decrease in EG and an increase in monoterpene hydrocarbons and isomenthone/menthone was observed upon infection by cucumber mosaic virus (Bruni et al. 2007). Several other authors have also reported a great diversity of essential oil composition between samples of different origin (Chae et al. 2005; Svoboda et al. 1995), but there is no complete explanation of the possible cause of this variation. In vitro ontogenetic changes in the composition of secondary metabolites, including volatiles, are known to occur in many plants-for example, mint (Phatak and Heble 2002) or basil (Lewinsohn et al. 2001), and the present observations suggest that phenylallyl and monoterpene biosynthesis in A. rugosa is developmentally regulated. On the growth regulator-free MS medium, pulegone was the single major compound (over 90\%), with a small proportion of limonene, which is the first committed intermediate of the menthane pathway. The hydrocarbon monoterpene fraction increased to
$20-50 \%$ in in vitro cultures on media containing PGRs, but in the presence of PIC the emission of limonene was lower than $\alpha$-pinene. The latter compound was detected only in low amounts in the seedlings and in cultures on PGR-free and IAA-supplemented media. The levels of menthane compounds, such as menthone/isomenthone (two enantiomers derived biosynthetically from pulegone) and pulegone, also differed significantly between cultures on IAA- and PIC-supplemented medium: menthone/isomenthone levels in PIC-supplemented medium were about double those on IAA-supplemented medium, while the pulegone level on the former was about one-fifth to onehalf that on the latter. These differences were lowest on KIN-containing medium and highest on TDZ-containing medium, but the influence of auxins was more evident than that of cytokinins.

Santos-Gomes and Fernandes-Ferreira (2003) reported that the essential oil composition of Salvia officinalis shoots was not influenced by the cytokinin composition of the various media, but the only auxin used in their study was 2,4-dichlorophenoxyacetic acid. Arikat et al. (2004) observed that there were slight deviations in major monoterpene proportions between $S$. fruticosa microshoots obtained on a single medium $(0.1 \mu \mathrm{M}$ gibberellic acid, $0.1 \mu \mathrm{M}$ 1-naphthaleneacetic acid, and $2 \mu \mathrm{M}$ BA) and in vivo plants, but the constituents were the same. In contrast, in vitro shoot cultures of thyme (Thymus vulgaris) differed in essential oil composition depending on composition of the plant hormones in the media (Affonso Ribeiro et al. 2009). Among three cytokinins (BA, KIN and zeatin) and IAA added at various concentrations, the latter at $1 \mu \mathrm{M}$ caused the most significant increase in thymol level and decrease in levels of hydrocarbon monoterpenes. The influence of different concentrations of cytokinins was less significant, and apparently one of the three tested concentrations was more efficient, albeit without any clear correlation.

In our study, supplementation with the natural auxin IAA or the synthetic PIC resulted in a markedly different response in monoterpene composition. However, due to the insufficient material yield we were unable to study the possible effects of other concentrations of PGRs on the composition of VOCs. The differences described here suggest some differential influence of the two types of auxins on monoterpene metabolism. However, very few details are known on the physiological mechanisms of action of the synthetic auxin PIC, which is a pyridine herbicide, and how these differ from those of the natural hormone IAA (Kelley and Riechers 2007). These differences should be further explored to reveal any quantitative correlation between the levels of exogenous auxins-rather than of cytokinins - and those of the monoterpene volatiles. In another study (Shin et al. 2001) on volatiles 
Table 2 Percentage composition of headspace volatiles of the field-grown plant and in vitro seedlings and shoot cultures of A. rugosa

\begin{tabular}{|c|c|c|c|c|c|c|c|c|c|c|c|c|}
\hline Peak no. & Constituent & $\mathrm{RI}_{\exp }$ & $\mathrm{RI}_{\text {lit }}^{\mathrm{a}}$ & Adult & Seedling & MS0 & BA/IAA & KIN/IAA & TDZ/IAA & $\mathrm{BA} / \mathrm{PIC}$ & KIN/PIC & TDZ/PIC \\
\hline 1. & Dimethylsulfide & 506 & $506^{\mathrm{b}}$ & 0.2 & $\mathrm{t}$ & $\mathrm{t}$ & 0.4 & $\mathrm{t}$ & $\mathrm{t}$ & 1.5 & 1.6 & 1.7 \\
\hline 2. & Pentanal & 705 & $707^{\mathrm{b}}$ & - & - & - & - & $\mathrm{t}$ & - & 0.1 & 0.4 & - \\
\hline 3. & Hex-2-enal & 828 & 831 & - & - & - & 0.2 & 0.3 & $\mathrm{t}$ & - & $\mathrm{t}$ & - \\
\hline 4. & Hex-3-en-1-ol & 838 & 851 & - & - & - & 0.1 & 0.1 & 0.1 & - & $\mathrm{t}$ & $\mathrm{t}$ \\
\hline 5. & Hex-2-en-1-ol & 850 & 861 & - & - & - & 0.1 & $\mathrm{t}$ & $\mathrm{t}$ & - & - & - \\
\hline 6. & $\alpha$-Thujene & 925 & 932 & - & - & - & $\mathrm{t}$ & - & $\mathrm{t}$ & $\mathrm{t}$ & $\mathrm{t}$ & 0.1 \\
\hline 7. & $\alpha$-Pinene & 933 & 936 & - & 1.3 & 0.1 & 5.5 & 2.2 & 1.6 & 13.9 & 13.7 & 25.9 \\
\hline 8. & Camphene & 938 & 950 & - & - & - & $\mathrm{t}$ & 0.1 & $\mathrm{t}$ & 0.1 & 0.4 & 1.0 \\
\hline 9. & Oct-1-en-3-ol & 965 & 962 & 0.2 & $\mathrm{t}$ & 0.1 & 0.1 & 0.2 & 0.1 & 0.1 & 0.1 & 0.1 \\
\hline 10. & Octan-3-one & 968 & 969 & 0.2 & - & 0.1 & - & - & - & - & - & - \\
\hline 11. & Sabinene & 970 & 973 & - & 0.1 & $\mathrm{t}$ & 0.2 & $\mathrm{t}$ & $\mathrm{t}$ & 0.2 & $\mathrm{t}$ & $\mathrm{t}$ \\
\hline 12. & $\beta$-Pinene & 974 & 978 & - & 0.1 & $\mathrm{t}$ & 0.4 & 0.1 & 0.1 & 0.9 & 0.9 & 1.7 \\
\hline 13. & Myrcene & 983 & 987 & $\mathrm{t}$ & 0.3 & 0.3 & 1.4 & 0.9 & 1.1 & 1.5 & 0.8 & 1.8 \\
\hline 14. & p-Cymene & 1,015 & 1,015 & - & $\mathrm{t}$ & $\mathrm{t}$ & 0.1 & $\mathrm{t}$ & $\mathrm{t}$ & 0.2 & 0.1 & 0.3 \\
\hline 15. & Limonene & 1,024 & 1,024 & 3.7 & 2.5 & 2.6 & 13.3 & 12.7 & 20.2 & 12.4 & 4.0 & 13.5 \\
\hline 16. & (Z)- $\beta$-Ocimene & 1,030 & 1,029 & - & $\mathrm{t}$ & 0.1 & $\mathrm{t}$ & 0.2 & 0.5 & 0.3 & - & 0.6 \\
\hline 17. & p-Cymenene & 1,077 & 1,076 & - & $\mathrm{t}$ & 0.1 & 0.1 & 0.2 & 0.1 & $\mathrm{t}$ & - & - \\
\hline 18. & Linalool & 1,086 & 1,086 & - & $\mathrm{t}$ & 0.2 & 0.1 & 0.1 & 0.1 & 0.1 & 0.1 & 0.1 \\
\hline 19. & Oct-1-en-3-yl acetate & 1,094 & 1,093 & 0.2 & $\mathrm{t}$ & $\mathrm{t}$ & 0.1 & 0.1 & $\mathrm{t}$ & 0.1 & 0.1 & $\mathrm{t}$ \\
\hline 20. & Menthone & 1,139 & 1,136 & - & $\mathrm{t}$ & $\mathrm{t}$ & 1.9 & 1.5 & 1.1 & 5.1 & 3.3 & 3.5 \\
\hline 21. & Isomenthone & 1,149 & 1,146 & - & $\mathrm{t}$ & 0.1 & 9.7 & 9.6 & 6.4 & 26.4 & 20.2 & 15.0 \\
\hline 22. & Menthofuran & 1,153 & 1,150 & - & 0.1 & $\mathrm{t}$ & $\mathrm{t}$ & $\mathrm{t}$ & 0.2 & $\mathrm{t}$ & 0.5 & 0.2 \\
\hline 23. & cis-Isopulegone & 1,156 & 1,148 & - & 0.1 & 1.2 & 0.4 & 0.4 & 0.3 & 0.6 & 0.8 & 0.9 \\
\hline 24. & trans-Isopulegone & 1,158 & 1,161 & - & 0.9 & 0.2 & 0.4 & 0.5 & 0.4 & 0.4 & 0.3 & $\mathrm{t}$ \\
\hline 25. & Estragol & 1,174 & 1,175 & 95.0 & 21.0 & $\mathrm{t}$ & - & 0.1 & - & - & - & - \\
\hline 26. & $\alpha$-Terpineol & 1,174 & 1,176 & - & - & $\mathrm{t}$ & $\mathrm{t}$ & $\mathrm{t}$ & - & $\mathrm{t}$ & $\mathrm{t}$ & - \\
\hline 28. & Decanal & 1,181 & 1,180 & - & - & - & - & 0.1 & - & - & - & 0.1 \\
\hline 29. & Verbenone & 1,186 & 1,183 & - & - & $\mathrm{t}$ & 0.3 & 0.1 & 0.2 & 0.3 & 0.2 & 0.5 \\
\hline 30. & Pulegone & 1,224 & 1,215 & - & 71.3 & 92.7 & 55.1 & 64.2 & 60.9 & 19.2 & 35.5 & 12.2 \\
\hline 31. & Piperitone & 1,227 & 1,226 & - & $\mathrm{t}$ & $\mathrm{t}$ & 0.4 & 0.2 & - & 0.6 & 0.4 & 0.4 \\
\hline 32. & 3-Methylpentyl angelate & 1,234 & 1,230 & - & - & - & - & - & - & - & - & 0.5 \\
\hline 33. & trans-Anethol & 1,258 & 1,262 & 0.2 & 0.2 & - & - & $\mathrm{t}$ & $\mathrm{t}$ & - & - & 0.7 \\
\hline 36. & trans-Pinocarvyl acetate & 1,281 & 1,287 & - & 0.2 & $\mathrm{t}$ & 0.1 & - & 0.1 & 0.1 & - & - \\
\hline 37. & Undecanal & 1,279 & 1,290 & - & - & - & $\mathrm{t}$ & $\mathrm{t}$ & - & 0.1 & 0.1 & 0.1 \\
\hline 38. & trans-Carvyl acetate & 1,312 & 1,318 & - & 0.4 & 0.4 & 0.6 & 0.6 & 0.6 & 0.7 & 0.2 & 0.2 \\
\hline 39. & Piperitenone & 1,320 & 1,318 & - & 0.5 & 0.7 & 0.3 & 0.4 & 0.5 & 0.6 & 0.1 & 0.3 \\
\hline 41. & $\delta$-Elemene & 1,340 & 1,340 & - & - & - & $\mathrm{t}$ & 0.1 & 0.1 & $\mathrm{t}$ & 0.2 & 0.1 \\
\hline 44. & Dodecanal & 1,386 & 1,389 & - & - & - & $\mathrm{t}$ & $\mathrm{t}$ & $\mathrm{t}$ & 0.4 & 0.1 & 0.5 \\
\hline 46. & $\beta$-Elemene & 1,395 & 1,389 & & - & $\mathrm{t}$ & 0.1 & - & $\mathrm{t}$ & 0.4 & 0.7 & 2.3 \\
\hline 47. & $\beta$-Caryophyllene & 1,430 & 1,421 & 0.2 & 0.2 & 0.1 & 1.1 & 0.9 & 0.5 & 0.6 & 0.1 & 0.5 \\
\hline 48. & $\alpha$-Humulene & 1,453 & 1,455 & - & $\mathrm{t}$ & $\mathrm{t}$ & $\mathrm{t}$ & $\mathrm{t}$ & $\mathrm{t}$ & $\mathrm{t}$ & $\mathrm{t}$ & $\mathrm{t}$ \\
\hline 51. & Germacrene D & 1,488 & 1,479 & 0.1 & 0.2 & 0.1 & 0.7 & 0.3 & 0.3 & 0.2 & - & - \\
\hline 52. & $(3 Z, 6 E)-\alpha$-Farnesene & 1,490 & 1,480 & - & $\mathrm{t}$ & - & 0.1 & $\mathrm{t}$ & $\mathrm{t}$ & 0.1 & - & - \\
\hline 53. & $\beta$-Selinene & 1,485 & 1,486 & - & - & - & - & - & - & - & 0.2 & 0.2 \\
\hline 54. & $\alpha$-Selinene & 1,494 & 1,494 & - & - & - & - & - & - & - & 0.3 & 1.0 \\
\hline 55. & Bicycogermacrene & 1,495 & 1,494 & $\mathrm{t}$ & 0.1 & 0.1 & 0.2 & 0.3 & 0.1 & 0.2 & - & - \\
\hline 57. & Citronellyl butyrate & 1,524 & 1,516 & - & - & - & - & 0.1 & 0.3 & - & 0.4 & - \\
\hline 58. & $\delta$-Cadinene & 1,516 & 1,520 & - & $\mathrm{t}$ & - & 0.2 & $\mathrm{t}$ & 0.1 & 0.2 & - & - \\
\hline
\end{tabular}


Table 2 continued

\begin{tabular}{|c|c|c|c|c|c|c|c|c|c|c|c|c|}
\hline Peak no. & Constituent & $\mathrm{RI}_{\mathrm{exp}}$ & $\mathrm{RI}_{\text {lit }}^{\mathrm{a}}$ & Adult & Seedling & MS0 & $\begin{array}{l}\text { BA/ } \\
\text { IAA }\end{array}$ & $\begin{array}{l}\text { KIN/ } \\
\text { IAA }\end{array}$ & $\begin{array}{l}\text { TDZ/ } \\
\text { IAA }\end{array}$ & $\begin{array}{l}\text { BA/ } \\
\text { PIC }\end{array}$ & $\begin{array}{l}\text { KIN/ } \\
\text { PIC }\end{array}$ & $\begin{array}{l}\text { TDZ/ } \\
\text { PIC }\end{array}$ \\
\hline 59. & Geranyl butyrate & 1,540 & 1,534 & - & - & - & - & - & 0.1 & $\mathrm{t}$ & 0.1 & 0.3 \\
\hline 64. & Octyl salicylate & 1,884 & - & - & - & & $\mathrm{t}$ & $\mathrm{t}$ & $\mathrm{t}$ & - & 0.4 & - \\
\hline 65. & $\begin{array}{l}\text { 3,3,5-Trimethyl-cyclohexyl } \\
\text { salicylate }\end{array}$ & 2,063 & 2,037 & - & - & & - & $\mathrm{t}$ & $\mathrm{t}$ & - & 0.1 & 0.4 \\
\hline 66. & Total content of aliphatic esters & & & 0.0 & 0.2 & 0.0 & 1.1 & 0.9 & 0.4 & 3.0 & 2.2 & 5.6 \\
\hline $\begin{array}{l}\text { Total } \\
\text { identified }\end{array}$ & & & & 100.0 & 99.7 & 99.2 & 95.0 & 97.6 & 96.4 & 89.3 & 88.8 & 92.4 \\
\hline
\end{tabular}

$R I$, Retention index; MSO, MS media not containing plant growth regulators; $t$, trace $(<0.05 \%)$

Values exceeding $2 \%$ are given in bold

${ }^{a}$ RI according to MassFinder 4.0

${ }^{\mathrm{b}}$ RI according to Wiley Register 8th edn

(extracted with dichloromethane) from the tissue culture of A. rugosa, the profile was also completely altered in callus compared to the mature plant. The occurrence of estragole at a low percentage $(0.58 \%$ compared to over $50 \%$ in an extract from leaves) and increases in monoterpene peaks were observed upon elicitation with jasmonic acid and methyl jasmonate. However, the quantitative relationships between the major monoterpenoids were not reported.

It may be speculated that not just developmental processes, but also stress mediators and hormonal regime can orchestrate the complex volatile biosynthesis in A. rugosa, resulting in significant variations in their composition. The mechanisms of these two apparently competitive major pathways leading to a predominance of either phenylallyls or monoterpenes need further exploration and may provide an interesting model for metabolic studies.

Acknowledgments This study was supported by a grant no. 1656 from the Medical University of Wroclaw. The authors thank Agata Biernat for cultivating and collecting the plants in the Botanical Garden of Medicinal Plants and Andrzej Dryś, director of the Mathematics and Statistics Section, Department of. Physical Chemistry, for advice on the statistical evaluation of experimental data.

Open Access This article is distributed under the terms of the Creative Commons Attribution Noncommercial License which permits any noncommercial use, distribution, and reproduction in any medium, provided the original author(s) and source are credited.

\section{References}

Adams RP (2007) Identification of essential oil components by gas chromatography/mass spectrometry, 4th edn. Allured Publishing, Carol Stream

Affonso Ribeiro V, Bizzo Ribeiro H, Lage Salgueiro CL, Sato A (2009) Influence of growth regulators in biomass production and volatile profile of in vitro plantlets of Thymus vulgaris L. J Agric Food Chem 57:6392-6395
Arikat NA, Jawad FM, Karam NS, Shibli RA (2004) Micropropagation and accumulation of essential oils in wild sage (Salvia fruticosa Mill). Sci Hortic 100:193-202

Bruni R, Bianchi A, Bellardi MG (2007) Essential oil composition of Agastache anethiodora Britton (Lamiaceae) infected by cucumber mosaic virus (CMV). Flavour Fragr J 22:66-70

Chae YA, Ohk HC, Song JS (2005) Variability of the volatile composition of Agastache rugosa in South Korea. Acta Hort 675:59-64

Dung NX, Cu LD, Thai NH, Moi LD, Hac LV, Leclerc PA (1996) Constituents of the leaf and flower oils of Agastache rugosa (Fisch. et Mey) O. Kuntze from Vietnam. J Essent Oil Res 8:135-138

Kelley BK, Riechers DE (2007) Recent developments in auxin biology and new opportunities for auxinic herbicide research. Pestic Biochem Physiol 89:1-11

Lewinsohn E, Ziv-Raz I, Dudai N, Tadmor Y, Lastochkin E, Larkov O, Chaimovitsh D, Ravid U, Putievsky E, Pichersky E, Shoham Y (2001) Biosynthesis of estragole and methyl-eugenol in sweet basil (Ocimum basilicum L.): developmental and chemotypic association of allylphenol $O$-methyltransferase activities. Plant Sci 160:27-35

Liu W, Chilcott CE, Reich RC, Hellmann GM (2000) Regeneration of Salvia sclarea via organogenesis. In Vitro Cell Dev Biol Plant 36:201-206

Magyar-Tabori K, Dobranszki J, Teixeira da Silva JA, Bulley SM, Hudak I (2010) The role of cytokinins in shoot organogenesis in apple. Plant Cell Tiss Organ Cult 101:251-267

Meszaros A, Bellon A, Pinter E, Horvath G (1999) Micropropagation of lemon balm. Plant Cell Tiss Organ Cult 57:149-152

Misra P, Chaturvedi HC (1984) Micropropagation of Rosmarinus officinalis L. Plant Cell Tiss Organ Cult 3:163-168

Morone-Fortunato I, Avato P (2008) Plant development and synthesis of essential oils in micropropagated and mycorrhiza inoculated plants of Origanum vulgare L. ssp. hirtum (Link) Ietswaart. Plant Cell Tiss Organ Cult 93:139-149

Murashige T, Skoog F (1962) A revised medium for rapid growth and bioassays with tobacco tissue cultures. Physiol Plant 15:473-497

Nitnaware KM, Naik DG, Nikam TD (2011) Thidiazuron-induced shoot organogenesis and production of hepatoprotective lignan phyllanthin and hypophyllanthin in Phyllanthus amarus. Plant Cell Tiss Organ Cult 104:101-110

Phatak SV, Heble RM (2002) Organogenesis and terpenoid synthesis in Mentha arvensis. Fitoterapia 73:32-39

Predieri S, Rapparini F (2007) Terpene emission in tissue culture. Plant Cell Tiss Organ Cult 91:87-95 
Santos-Gomes PC, Fernandes-Ferreira M (2003) Essential oils produced by in vitro shoots of sage (Salvia officinalis L.). J Agric Food Chem 51:2260-2266

Shin S (2004) Essential oil compounds from Agastache rugosa as antifungal agents against Trichophyton species. Arch Pharm Res 27:295-299

Shin SH, Kim YS, Kang CA (2001) Production of volatile oil components by cell culture of Agastache rugosa O. Kuntze. Nat Prod Sci 7:120-123

Song JH, Kim MJ, Kwon HD, Park IH (2001) Antimicrobial activity and components of extracts from Agastache rugosa during growth period. J Food Sci Nutr 6:10-15

Sood H, Chauhan RS (2010) Biosynthesis and accumulation of a medicinal compound, Picroside-I, in cultures of Picrorhiza kurroa Royle ex Benth. Plant Cell Tiss Organ Cult 100:113-117
Sudria C, Pinol MT, Palazon J, Cusido RM, Vila R, Morales C, Bonfill M, Canigueral S (1999) Influence of plant growth regulators on the growth and essential oil content of cultured Lavandula dentata plantlets. Plant Cell Tiss Organ Cult 58:177-184

Svoboda KP, Gough J, Hampson J, Galambosi B (1995) Analysis of the essential oils of some Agastache species grown in Scotland from various seed sources. Flavour Fragr J 10:139-145

Weyerstahl P, Marschall H, Manteuffel E (1992) Volatile constituents of Agastache rugosa. J Essent Oil Res 4:585-587

Wilson LA, Senecha NP, Widrlechner MP (1992) Headspace analysis of the volatile oils of Agastache. J Agric Food Chem 40: $1362-1366$ 